\title{
BLALOCK-TAUSSIG ANASTOMOSIS FOR TETRALOGY OF FALLOT A TEN-TO-FIFTEEN YEAR FOLLOW-UP
}

\author{
BY \\ A. M. HARRIS, N. SEGEL, AND J. M. BISHOP \\ From the Department of Medicine, Queen Elizabeth Hospital and University of Birmingham, Birmingham \\ Received May 30, 1963
}

The mortality rate for total correction of Fallot's tetralogy on cardiac bypass with or without a Blalock-Taussig anastomosis is still relatively high (Kirklin et al., 1959; Lillehei et al., 1957; Taussig et al., 1962). Favourable reports concerning the results of the Blalock-Taussig procedure in patients followed for five to ten years have been published (Taussig and Bauersfeld, 1953; Campbell and Deuchar, 1953; White et al., 1956; Rumel, 1958; Brock, 1959; Shumacker and Mandelbaum, 1960). While total correction is the ideal, the mortality rate must be weighed against the long-term beneficial effects of the safer Blalock-Taussig operation.

In the present investigation we have studied the results of the Blalock-Taussig operation performed ten or more years ago in the United Birmingham Hospitals and have compared them with the outcome in a group of untreated patients with Fallot's tetralogy over the same period. We were also interested in the effects of a left-to-right shunt, created after birth, on the underperfused pulmonary circulation, since the occasional development of pulmonary hypertension has been reported in some of these patients (Leeds, 1958; Ross, Taussig, and Evans, 1958; Epstein and Naji, 1960; Ferencz, 1960; Paul, Miller, and Potts, 1961; McGaff, Ross, and Braunwald, 1962).

\section{Patients AND Method}

Between the years 1948 and 1952 the diagnosis of Fallot's tetralogy was made in 42 patients. The diagnosis was based upon clinical signs and confirmed by cardiac catheterization and/or angiocardiography both before operation and again during the present investigation. In 30 of the patients, the disability was so great or was increasing so fast that operation was performed in or before the year 1952 . The remaining 12 patients were less disabled and operation was not therefore recommended. The subsequent course of these two groups, henceforth referred to as the treated and untreated groups respectively, has been followed.

The treated group consisted of 30 patients, and $20(67 \%)$ have survived for a mean period of 11.9 years (range 10-15). Their ages at the time of operation ranged between 4 and 37 years (mean 10.3). The remaining 10 are known to have died. Of the surviving patients, 19 have been studied and one refused investigation, although we have full details of his present clinical condition. There were 13 male and 7 female patients whose ages ranged from 14 to 37 years (mean 22.2) at the time of study. The untreated group comprised 12 patients ( 6 male and 6 female) whose ages ranged between 3 and 27 years (mean $11 \cdot 7$ ) when first seen. Excluded from this study were patients diagnosed in or before 1952, not operated on then, but operated upon since 1952 .

At the time of the follow-up investigation in the treated group each patient was examined and exercise tolerance was graded according to the New York Heart Association (1953). Special investigations included hæmoglobin concentration and hæmatocrit measurement, electrocardiogram, phonocardiogram, and chest radiograph. Seventeen patients had cardiac catheterization which was performed by the usual method. Intravascular pressures were measured by capacitance manometers, the zero reference level for pressures being $10 \mathrm{~cm}$. above the plane of the table. All pressures were averaged over at least three respiratory cycles. Expired gas was collected for three minutes in a Tissot spirometer and analysed in a Scholander 
apparatus. Three samples each of arterial and right pulmonary arterial blood were taken for determination of oxygen saturation (Wade et al., 1953). Blood samples for estimation of oxygen saturations were taken at various sites commencing distally in the right and left pulmonary arteries, which were entered in 15 patients, and ending in the superior vena cava.

The patients then exercised on a bicycle ergometer for five minutes at a constant load in the supine position. Oxygen uptake, right pulmonary and brachial arterial blood samples for oxygen saturation were measured between the fourth and fifth minutes of exercise, and intravascular pressures were recorded immediately before and after the measurement of oxygen uptake.

\section{RESULTS}

Treated Group. Analysis of the age distribution and results of the Blalock-Taussig operation in the 30 patients are shown in Tables I and II: 20 (67\%) have survived for a mean period of 11.9 years (range 10-15), and the remaining 10 are known to have died. Only one patient died at the time of operation, and another patient died during a second operation one year later, following thrombosis of the first anastomosis. Four patients died in congestive cardiac failure within six months of operation. One died in his eighth post-operative year and three in their tenth postoperative year, in congestive cardiac failure. These last four patients were improved by operation and were relatively well until a few months before death. Necropsy was performed in only one of these patients (Patient No. 30, Table II), and this revealed histological features compatible with severe pulmonary arterial hypertension (Fig. 1). Direct intravascular pressures were not obtained, although a chest radiograph taken three months before death revealed a large heart and a pulmonary vascular pattern highly suggestive of pulmonary arterial hypertension (Fig. 2).

Effort Tolerance. After operation effort tolerance improved in all the patients, including four who have since died. In most the clinical improvement was immediate, but some continued to improve further over the ensuing years, and all have maintained their improved state.

At the time of the present investigation all the survivors had improved from class 3 or 4 to class 1 or 2 . In addition, the tendency to squatting and cyanotic attacks has considerably diminished or disappeared. They were able to lead relatively normal lives in that they were either doing a full day's work or attending school. Some of the younger patients participated in games at school and some of the adults were able to dance.

Physical Examination. On examination all the patients were centrally cyanosed at rest and all except Patient 2 had clubbing of the fingers and toes. In three the clubbing was less marked on the side of the subclavian artery ligation. Of the patients who had had the operation before the age of 11 years 13 had a slightly shorter left arm with reduction in muscle mass as compared with the right. An example is shown in Fig. 3. There was clinical evidence of right ventricular hypertrophy and a systolic thrill in the pulmonary area with a typical systolic ejection murmur along the left parasternal border. Evidence of patency of the anastomosis as judged by the presence of a continuous murmur in the second interspace was present in all the patients.

General Investigation. The hæmoglobin concentration ranged between 15.0 and $21.7 \mathrm{~g} . / 100 \mathrm{ml}$. (mean 18.8) and hæmatocrit between 50 and 76 per cent.

The electrocardiogram showed right ventricular hypertrophy. All the patients were in sinus rhythm; 4 had right bundle-branch block, and 13 had " $P$ " waves indicative of right atrial enlargement; 5 had evidence of left ventricular hypertrophy with " $R$ " waves greater than $25 \mathrm{~mm}$. in the left præcordial leads.

Phonocardiography confirmed the clinical auscultatory findings.

In none of the patients was there radiological evidence of cardiac enlargement. The cardiothoracic ratio was less than 50 per cent in all, and the left pulmonary artery and its branches were more prominent and better filled than the right in most.

Intravascular Pressures. The results of measurements of pulmonary arterial and right ventricular systolic pressures, together with the percentage oxygen saturations of pulmonary arterial blood at rest are shown in Fig. 4. All had evidence of pulmonary stenosis with a marked difference in systolic 
TABLE I

Age Distribution and functional Cardiac Status of Surviving Patients Before and After BlaLOCK-TAUSSIg OPERATION

\begin{tabular}{|c|c|c|c|c|c|c|}
\hline \multirow{3}{*}{$\begin{array}{l}\text { Patient No. } \\
\text { and sex }\end{array}$} & \multirow{3}{*}{$\begin{array}{c}\text { Age at } \\
\text { operation } \\
\text { (yr.) }\end{array}$} & \multirow{3}{*}{$\begin{array}{l}\text { Present } \\
\text { age } \\
\text { (yr.) }\end{array}$} & \multicolumn{4}{|c|}{ Functional classification } \\
\hline & & & \multicolumn{2}{|c|}{ Class before operation } & \multicolumn{2}{|c|}{ Class after operation } \\
\hline & & & 3 & 4 & 1 & 2 \\
\hline $\begin{array}{rl}1 & \mathrm{M} \\
2 & \mathrm{M} \\
3 & \mathrm{M} \\
4 & \mathrm{M} \\
5 & \mathrm{~F} \\
6 & \mathrm{M} \\
7 & \mathrm{M} \\
8 & \mathrm{M} \\
9 & \mathrm{M} \\
10 & \mathrm{M} \\
11 & \mathrm{M} \\
12 & \mathrm{M} \\
13 & \mathrm{~F} \\
14 & \mathrm{~F} \\
15 & \mathrm{~F} \\
16 & \mathrm{M} \\
17 & \mathrm{M} \\
18 & \mathrm{~F} \\
19 & \mathrm{~F} \\
20 & \mathrm{~F}\end{array}$ & $\begin{array}{r}7 \\
17 \\
5 \\
5 \\
19 \\
17 \\
7 \\
14 \\
4 \\
16 \\
5 \\
6 \\
4 \\
6 \\
27 \\
9 \\
5 \\
4 \\
11 \\
18\end{array}$ & $\begin{array}{l}18 \\
31 \\
15 \\
19 \\
34 \\
27 \\
18 \\
24 \\
18 \\
28 \\
18 \\
18 \\
14 \\
16 \\
37 \\
19 \\
17 \\
18 \\
24 \\
31\end{array}$ & $\begin{array}{l}+ \\
+ \\
+ \\
+ \\
+ \\
+ \\
+ \\
+ \\
+ \\
+ \\
+ \\
+ \\
+ \\
+ \\
+ \\
+ \\
+ \\
+\end{array}$ & $\begin{array}{l}+ \\
+\end{array}$ & $\begin{array}{l}+ \\
+ \\
+ \\
+ \\
+ \\
+ \\
+ \\
+ \\
+ \\
+\end{array}$ & $\begin{array}{l}+ \\
+ \\
+ \\
+ \\
+ \\
+ \\
+ \\
+ \\
+ \\
+\end{array}$ \\
\hline Mean .. & $10 \cdot 3$ & $22 \cdot 2$ & & & & \\
\hline
\end{tabular}

TABLE II

Age Before and After Operation and Cause of Death in the Patients who Died

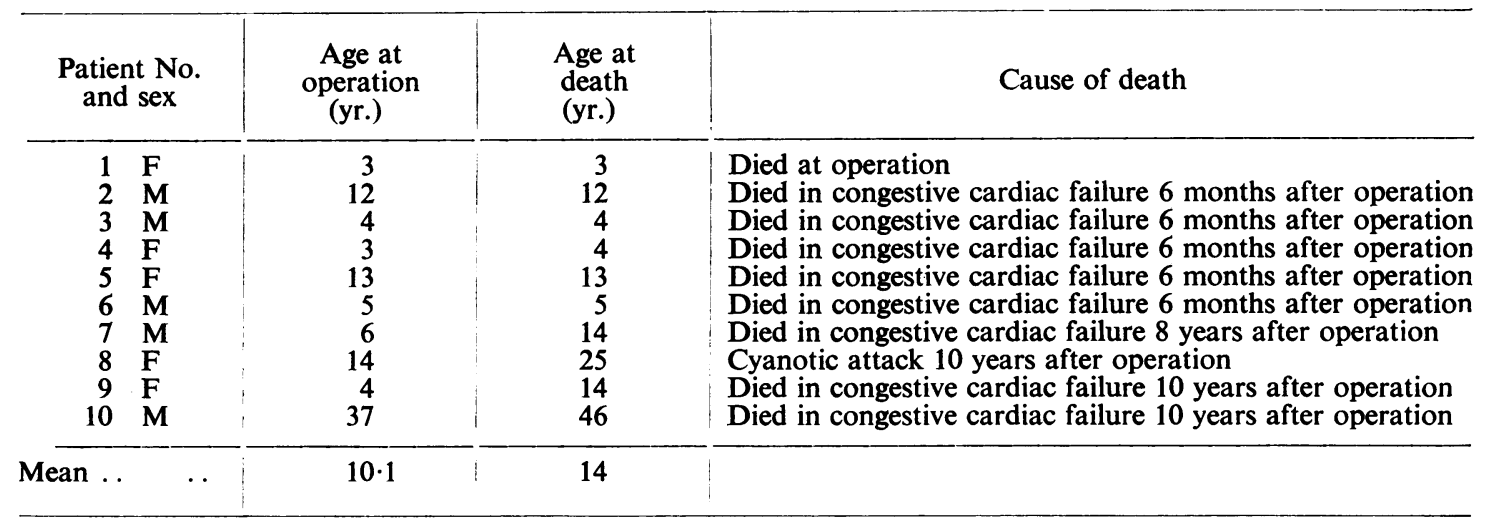

pressure across the pulmonary valve. The right ventricular systolic pressure ranged between 80 and $170 \mathrm{~mm} . \mathrm{Hg}$ (mean $111 \mathrm{~mm} . \mathrm{Hg}$ ). The patient who had a right ventricular systolic pressure of 170 $\mathrm{mm} . \mathrm{Hg}$ had associated systemic arterial hypertension. In all but one patient the pulmonary systolic pressure ranged between 10 and $25 \mathrm{~mm}$. $\mathrm{Hg}$, and the average pulmonary mean pressure was $12 \mathrm{~mm}$. Hg. The remaining patient (No. 2) had a moderately raised pulmonary arterial pressure (mean $26 \mathrm{~mm} . \mathrm{Hg}$ ). The pulmonary wedge pressure was within the normal range in all. During exercise the average pulmonary arterial mean pressure increased by $8 \mathrm{~mm}$. $\mathrm{Hg}$, and the pulmonary 


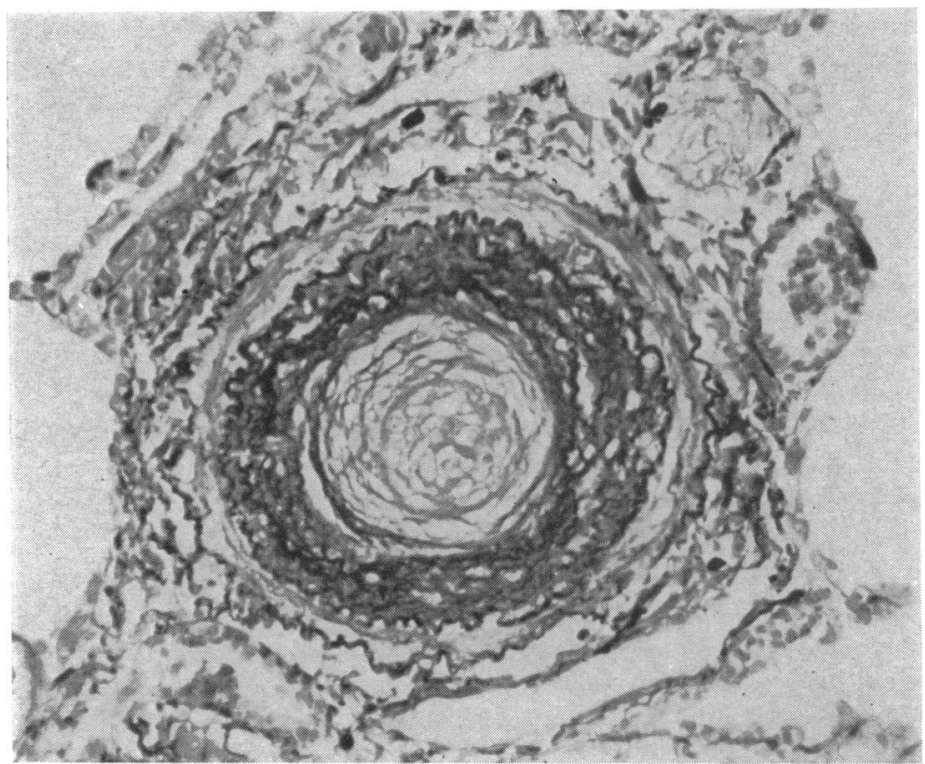

Fig. 1.-Transverse section of a muscular pulmonary artery from Patient No. 30, showing medial hypertrophy and occlusion of the lumen by intimal fibro-elastosis, Grade 3 (Heath et al., 1959). (Verhoeff-van Gieson $\times 250$ ).

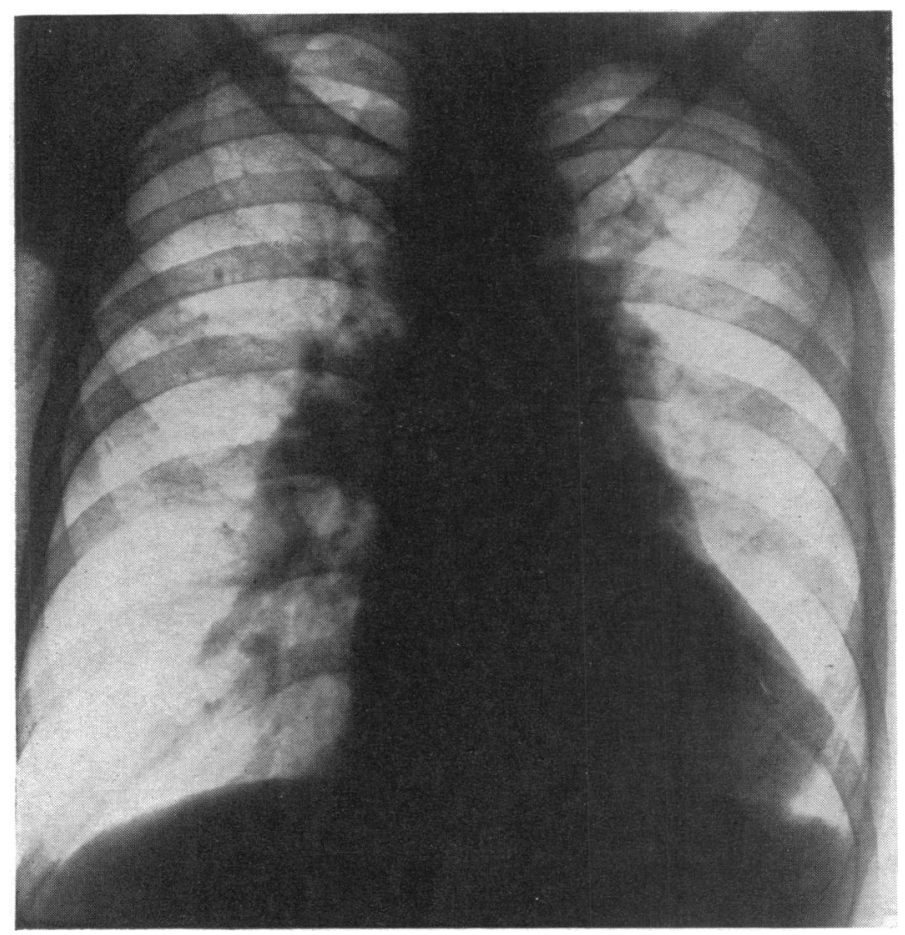

Fig. 2.-Chest radiograph of Patient No. 30 taken three months before death. The main pulmonary arteries are prominent with dilatation of the right and left branches and of the first divisions. There is generalized enlargement of the heart. 


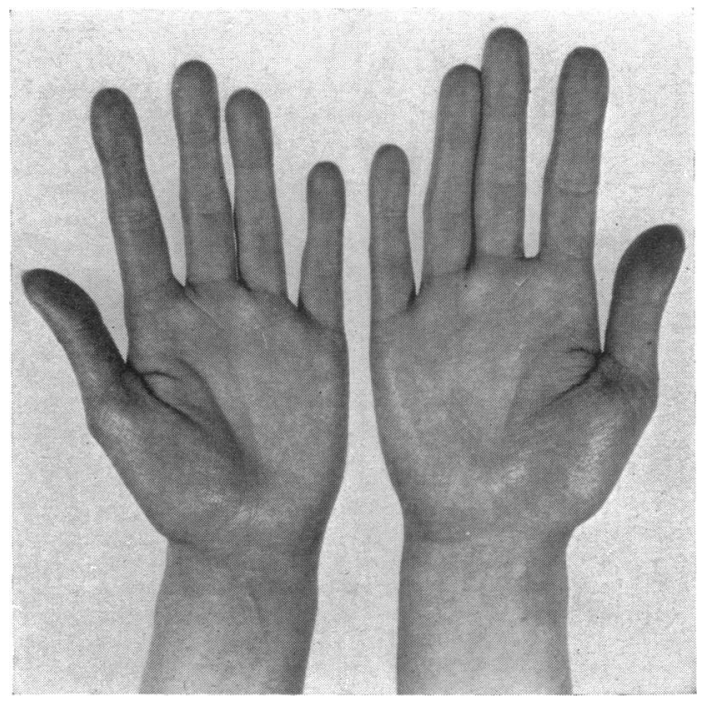

Fig. 3.-Hands of Patient No. 17: the left hand (side of anastomosis) is smaller than the right.

wedge pressure remained unchanged. In the patient with mild pulmonary hypertension the pulmonary arterial mean pressure increased by $10 \mathrm{~mm}$. $\mathrm{Hg}$.

Clinically and radiologically there was no evidence to suggest that the 3 patients who were not catheterized had severe pulmonary hypertension.

Blood Oxygen Saturation. Evidence of patency of the anastomosis was obtained since the left pulmonary arterial oxygen saturation was higher than the right in all the patients catheterized (Fig. 4). The brachial arterial oxygen saturation ranged between 90 and 76 per cent at rest. During exercise the arterial oxygen saturation always fell.

Oxygen Uptake. The oxygen uptake at rest ranged between 103 and $214 \mathrm{ml} . / \mathrm{min} . / \mathrm{m} .{ }^{2}$ (mean 173; S.D. 29.2). In 10 normal subjects studied in this laboratory (Donald et al., 1953) the mean oxygen uptake at rest was $140 \mathrm{ml} . / \mathrm{min} . / \mathrm{m}^{2}$ (S.D. $\left.22 \cdot 7\right)$, which is significantly less $(\mathrm{p}=<0.01)$ than
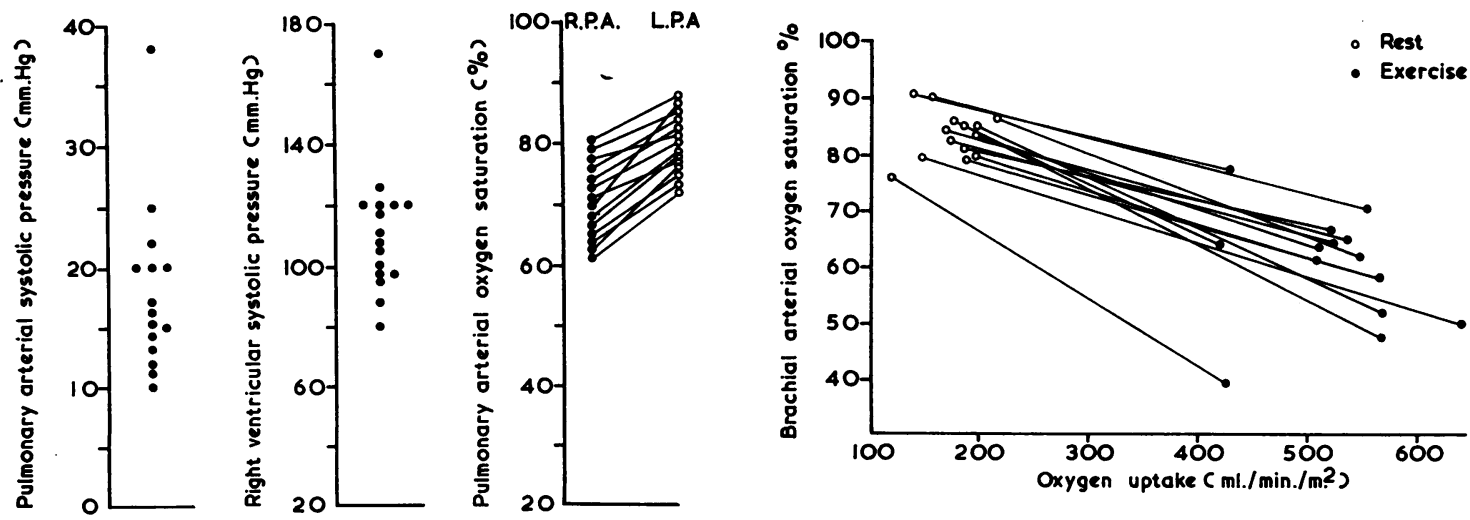

Fig. 4.-Values for pulmonary arterial and right ventricular systolic pressures and pulmonary arterial oxygen saturations at rest in 15 patients. R.P.A. $=$ right pulmonary artery; L.P.A.=left pulmonary artery.

Fig. 5.-Brachial arterial oxygen saturation plotted against oxygen uptake at rest and during exercise in 14 patients. 
the oxygen uptake in the patients. The mean ventilation at rest ranged from 3.49 to $8.491 . / \mathrm{min}$. (mean 5.1; S.D. 1.37 1./min.) and the mean R.Q. was 0.78 (S.D. 0.037 ) and ranged from 0.73 to 0.81 .

During exercise the oxygen uptake ranged between 420 and $640 \mathrm{ml} . / \mathrm{min} . / \mathrm{m} .^{2}$ (mean 518; S.D 63.1) and was achieved without distress.

The brachial arterial oxygen saturation plotted against the oxygen uptake at rest and during exercise is shown in Fig. 5. In general the fall in arterial saturation was related to the severity of the exercise as judged by the oxygen uptake.

Untreated Patients. Of the 12 untreated patients, $9(75 \%)$ have died and 3 are still alive. The ages at death ranged between 5 and 30 years (mean 13.1). Most appeared to have died in congestive cardiac failure but autopsy was not obtained in any, and there was no clinical evidence of severe pulmonary arterial hypertension. The 3 surviving patients are in functional class 2 , and their present ages are 18, 23, and 39 years.

\section{Discussion}

The natural life expectancy of patients with Fallot's tetralogy is variable. Most patients who have this malformation die during childhood but survivals as long as 69 years have been reported (Bain, 1954). Analysis of 115 patients with Fallot's tetralogy in Abbott's series (1936) revealed a mean survival of 12 years, but few survive 20 years (Keith, Rowe, and Vlad, 1958). In the untreated group of the present series, 75 per cent have died and their mean age at death was $13 \cdot 1$ years. In the treated patients the survival rate was 67 per cent, and the mean age of the survivors is $22 \cdot 2$ years. The difference between the survival rates for the treated and untreated groups was significant at the 5 per cent level. Furthermore the survivors of the treated group are all greatly improved, leading relatively normal lives and are able to perform without difficulty a moderate degree of exercise both as judged by history and the oxygen uptake. These patients were all severely disabled at the time of operation and judging by the mean survival of untreated patients (Keith et al., 1958) they might not be expected to have survived so long. Taussig et al. (1962) have reported that although continued improvement occurred in all survivors five years after operation, 46 per cent of their patients followed for 10 to 13 years after operation had failed to maintain clinical improvement. To date there is no evidence of deterioration in the survivors of this series. Paul et al. (1961), have reported that clinical improvement has been maintained 11 to 13 years after aortic-pulmonary anastomosis.

The mortality for total correction of Fallot's tetralogy on cardiac bypass has ranged between 10 and 75 per cent (Lillehei et al., 1957; Kirklin et al., 1959; Brock, 1959). The mortality rate for the Blalock-Taussig operation is of the order of 2 per cent (Taussig et al., 1962). Furthermore it is apparent that incomplete correction is neither uncommon nor without serious sequelæ (M. Gotsman, 1963, personal communication). It is clear from this series that the Blalock-Taussig procedure improves the survival and clinical conditions of patients with Fallot's tetralogy who are severely disabled. Unless the mortality rate for total correction considerably improves in the near future, the Blalock-Taussig operation should be preferred, at least in childhood. Furthermore, since clinical improvement has been adequately maintained in all the surviving patients and the heart size radiologically has remained within normal limits, there is no indication for complete correction at present. The indication for further surgical intervention should be based upon rapid deterioration in the clinical state (increased cyanosis and decreased effort tolerance) and an increase of the heart size.

Pulmonary hypertension occurred in one of the treated survivors, who died in his tenth postoperative year, and might have been present in the seven others who died, although there was no clinical evidence, at least, of severe pulmonary hypertenion just before death. Since it was clinically not possible to detect minor degrees of pulmonary arterial hypertension, the incidence of this complication in this series cannot be assessed. Nor is it possible to determine the overall incidence from 
other reported series, since these have usually been concerned with selected patients with pulmonary hypertension (Leeds, 1958; Ross et al., 1958; Epstein and Naji, 1960; McGaff et al., 1962).

Apart from the catheter findings there were no special clinical features that distinguished the single patient with mild pulmonary hypertension from the rest. The mechanism of pulmonary hypertension following a Blalock-Taussig anastomosis is not clear. It is not likely to be due to a large pulmonary blood flow that might be the cause in septal defects, since the shunt produced by operation would at most increase pulmonary flow to within normal or slightly higher limits. It has been suggested that even a small increase in blood flow through a previously underperfused and possibly abnormal pulmonary vascular tree might lead to pulmonary hypertension, since the vessels are relatively incapable of further distension (Heath et al., 1959; Wagenvoort, DuShane, and Edwards, 1960). In some patients the presence of pulmonary arteriolar thrombi, presumably due to the low pulmonary intravascular pressures and flow (Rich, 1948), might also be an important factor in the pathogenesis of pulmonary hypertension when the pulmonary flow is increased at operation.

In three patients, clubbing of the fingers was less on the side of the sub-clavian artery ligation. This has been observed by Campbell and Deuchar (1953) and has been attributed to a reduction in limb blood flow (Lovell, 1950; Wilson, 1952). The reduction in arm size on the side of the anastomoses has not been previously commented upon, although this is not unexpected when the operation is carried out at an early age.

The resting oxygen uptake in the treated group was greater than the expected normal range. Conflicting reports have been published concerning the oxygen uptake in Fallot's tetralogy and other cyanotic heart conditions. Bing et al. (1948) found the oxygen uptake to be low while others have found it normal (Ernsting and Shephard, 1951; Davison, Armitage, and Arnott, 1953). Some of these patients were studied again after the Blalock-Taussig operation, and a rise in the oxygen uptake was observed (Bing et al., 1948; Davison et al., 1953). The mechanism of the increase in oxygen uptake remains obscure.

Unfortunately since autopsies were not obtained in the 9 untreated and 9 treated patients who died, we were unable to determine the precise cause of death. Undoubtedly, the most common cause of death in infancy and early childhood is "syncope." Bacterial endocarditis and cerebral abscesses account for 20 per cent and intercurrent infection is responsible for most of the remainder (Wood, 1956). In a series of 117 autopsies performed on patients with Fallot's tetralogy who had a Blalock-Taussig operation the commonest cause of death immediately after operation was congestive cardiac failure. The incidence of congestive cardiac failure as a cause of death remained high in those who died one or more years after operation. The anastomosis remained patent in 108 of the 117 patients investigated. The incidence of severe pulmonary arteriolar thrombotic lesions, characteristic of the unoperated patients, was low. In patients who had a good anastomosis initially, but who lost their clinical improvement with growth, there was a tendency towards the recurrence of the thrombotic lesions. Only three patients had evidence of severe pulmonary hypertension (Ferencz, 1960).

\section{SUMMARY}

Thirty patients with Fallot's tetralogy who have had a Blalock-Taussig operation performed ten or more years ago have been studied: 67 per cent have survived, are clinically improved, and leading relatively normal lives. In a group of untreated patients followed for the same period of time, 25 per cent have survived.

The Blalock-Taussig operation has a low mortality and the results are good. Since the mortality for total correction of Fallot's tetralogy is still high, the former operation is to be preferred, at least in childhood.

Two patients who developed pulmonary hypertension are described.

We wish to thank Professor A. L. d'Abreau, Mr. J. L. Collis, Dr. Clifford Parsons, and Mr. L. D. Abrams for permission to study their patients. Thanks are due to Dr. O. Brenner for the phonocardiography and to Dr. D. Heath for 
the pathology reports. We also wish to thank Staff Nurse M. Booth, Mrs. P. Furness, Miss S. Pepper, and Miss G. Gerrard for their technical assistance.

\section{REFERENCES}

Abbott, M. E. (1936). Atlas of Congenital Cardiac Disease. American Heart Association, New York.

Bain, G. O. (1954). Tetralogy of Fallot: Survival to seventieth year. Arch. Path., 58, 176.

Bing, R. J., Vandam, L. D., Handelsman, J. C., Campbell, J. A., Spencer, R., and Griswold, H. E. (1948). Physiological studies in congenital heart disease. VI. Adaptations to anoxia in congenital heart disease with cyanosis. Johns Hopk. Hosp. Bull., 83, 439.

Brock, R. (1959). Editorial. Direct operations in tetralogy of Fallot. Amer. J. Cardiol., 3, 1.

Campbell, M., and Deuchar, D. (1953). Results of the Blalock-Taussig operation in 200 cases of morbus cæruleus. Brit. med. J., 1, 349.

Davison, P. H., Armitage, G. H., and Arnott, W. M. (1953). The mechanisms of adaption to a central venousarterial shunt. Brit. Heart J., 15, 221.

Donald, K. W., Bishop, J. M., Cumming, G., and Wade, O. L. (1953). The effect of nursing positions on the cardiac output in man. Clin. Sci., 12, 199.

Epstein, S., and Naji, A. F. (1960). Pulmonary artery aneurysm with dissection after Blalock operation for tetralogy of Fallot. Amer. J. Cardiol., 5, 560.

Ernsting, J., and Shephard, R. J. (1951). Respiratory adaptations in congenital heart disease. J. Physiol. (Lond.), $112,332$.

Ferencz, C. (1960). The pulmonary vascular bed in tetralogy of Fallot. II. Changes following a systemic-pulmonary arterial anastomosis. Johns Hopk. Hosp. Bull., 106, 100.

Heath, D., DuShane, J. W., Wood, E. H., and Edwards, J. E. (1959). The structure of the pulmonary trunk at different ages and in cases of pulmonary hypertension and pulmonary stenosis. J. Path. Bact., 77, 443.

Keith, J. D., Rowe, R. D., and Vlad, P. (1958). Heart Disease in Infancy and Childhood. Macmillan, New York.

Kirklin, J. W., Ellis, F. H., McGoon, D. C., DuShane, J. W., and Swan, H. J. C. (1959). Surgical treatment for the tetralogy of Fallot by open intracardiac repair. J. thorac. Surg., 37, 22.

Leeds, S. E. (1958). The tetralogy of Fallot in older persons up to the fifth decade. Results of subclavian-pulmonary anastomosis with a 5- to 10-year follow-up. Amer. J. Surg., 96, 234.

Lillehei, C. W., Warden, H. E., DeWall, R. A., Stanley, P., and Varco, R. L. (1957). Cardiopulmonary by-pass in surgical treatment of congenital or acquired cardiac disease. Arch. Surg., 75, 928.

Lovell, R. R. H. (1950). Observations on the structure of clubbed fingers. Clin. Sci.9, 299.

McGaff, C. J., Ross, R. S., and Braunwald, E. (1962). The development of elevated pulmonary vascular resistance in man following increased pulmonary blood flow from systemic-pulmonary anastomoses. Amer. J. Med., 33, 201.

New York Heart Association (1953). Nomenclature and Criteria for Diagnosis of Diseases of the Heart, 5th ed. New York.

Paul, M. H., Miller, R. A., and Potts, W. J. (1961). Long-term results of aortic-pulmonary anastomosis for tetralogy of Fallot. Circulation, 23, 525 .

Rich, A. R. (1948). A hitherto unrecognized tendency to the development of widespread pulmonary vascular obstruction in patients with congenital pulmonary stenosis (tetralogy of Fallot). Johns Hopk. Hosp. Bull., 82, 389.

Ross, R. S., Taussig, H. B., and Evans, M. H. (1958). Late hemodynamic complications of anastomotic surgery for treatment of the tetralogy of Fallot. Circulation, 18, 553.

Rumel, W. R. (1958). The surgical treatment of tetralogy of Fallot. Dis. Chest., 34, 103.

Shumacker, H. B., and Mandelbaum, I. (1960). Results of shunt procedures in tetralogy of Fallot. Surgery, 47, 320.

Taussig, H. B., and Bauersfeld, S. R. (1953). Follow-up studies on the first 1,000 patients operated on for pulmonary stenosis or atresia. Ann. intern. Med., 38, 1.

- Crawford, H., Pelargonio, S., and Zacharioudakis, S. (1962). Ten to thirteen year follow-up on patients after a Blalock-Taussig operation. Circulation, 25, 630 .

Wade, O. L., Bishop, J. M., Cumming, G., and Donald, K. W. (1953). A method for the rapid estimation of the percentage oxygen saturation and oxygen content of blood. Brit. med. J., 2, 902.

Wagenvoort, C. A., DuShane, J. W., and Edwards, J. E. (1960). Hypertensive pulmonary arterial lesions as a late result of anastomosis of systemic and pulmonary circulations. Proc. Mayo Clin., 35, 186.

White, B. D., McNamara, D. G., Bauersfeld, S. R., and Taussig, H. B. (1956). Five year post-operative results of first 500 patients with Blalock-Taussig anastomosis for pulmonary stenosis or atresia. Circulation, $14,512$.

Wilson, G. M. (1952). Local circulatory changes associated with clubbing of the fingers and toes. Quart.J. Med., 21, 201.

Wood, P. (1956). Diseases of the Heart and Circulation, 2nd ed. Eyre and Spottiswoode, London. 